\title{
La fuerza configuradora de la imaginación en el tiempo de la auto-afección de la mismidad: Kant y Heidegger
}

\author{
JUAN JOSÉ GARRIDO PERIÑÁN* \\ Universidad de Sevilla \\ jigarper@us.es
}

\begin{abstract}
Resumen
En este artículo de investigación trataré de repensar, dentro de la intuición marcada por Heidegger en su interpretación de Kant (Crítica de la Razón Pura), el papel que juega la noción de imaginación (trascendental), en su vinculación inexorable, por un lado, con la apercepción trascendental, y con el tiempo, por otro, a fin de alcanzar, al menos, un esbozo temático de tal imaginación en términos de auto-afección radical del sí-mismo. Y todo ello para mostrar la posibilidad de una lectura interpretativa que haga valer la importancia, justamente, de un sí mismo y/o mismidad.
\end{abstract}

Palabras claves: Imaginación, mismidad, Kant, Heidegger.

\section{The formative force of the imagination in the time of self-affection of selfhood: Kant and Heidegger}

\begin{abstract}
In this paper, I will try to rethink. Heidegger's interpretation of the role of transcendental imagination within his understanding of Kant's Critique of Pure Reason. My paper focuses on the connection between transcendental apperception on the one hand and the time on the other. In this sense, I will try to develop a thematic outline of such imagination in terms of radical selfaffection of Selfhood. And this in order to show the possibility of an interpretative reading that asserts the importance, precisely, of a self and/or selfhood.
\end{abstract}

Keywords: Imagination, selfhood, Kant, Heidegger.

\footnotetext{
* Personal Docente e Investigador (PDI) en la Universidad de Sevilla (VI Plan Propio de Investigación y Transferencia), Doctor en Filosofía con Mención Internacional (http://jigarridoperinan.es/). El artículo de investigación se realiza al amparo de las investigaciones desarrolladas por el Proyecto I+D (Excelencia): "Dinámicas del cuidado y lo inquientante. Figuras de lo inquietante en el debate fenomenológico contmporáneo y las posibilidades de una orientación filosófica. Configuración teórica y metodológica" (FFI2017/83770-P), financiado por el Ministerio de Innovación, Ciencia y Universidades del Reino de España.
} 


\section{INTRODUCCIÓN}

La intuición, un poco heterodoxa ${ }^{1}$ para el kantismo más dogmático, que tuvo Heidegger en su lectura de $\mathrm{Kr}^{2}$, a saber: interpretando esta obra como ajena a la teoría el conocimiento, en un compromiso de elucidación del problema esencial de la metafísica, el cual estribaba en la fundamentación de la subjetividad del sujeto (Dasein), basada en la finitud de su inexorable "temporalidad"3 [Zeitlichkeit] (Heidegger, 1991: 214). En Sein und

1 Heterodoxa a razón de discrepar totalmente de las escuelas neokantianas, de origen alemán, de su época. Este neokantismo se ejerció, en Alemania, en el centro de las universidades de Berlín, Heidelberg y Jena, desplegándose con mayor brío sobre tres afluentes: a) vía naturalización del criticismo, como la que llevó a cabo J.K. Fries; b) desde Marburgo, P. Natorp o N. Hartmann, entre otros, ejercieron una interpretación de Kant de carácter netamente logicista, en este sentido -al contrario que Heidegger-, haciendo valer la edición segunda de la Kritike der reinen Vernunft, conocida con la signatura de "B", donde la imaginación es desconectada del tiempo, y proyectada marginalmente sobre la capacidad espontanea del entendimiento; c) W. Windelband o H. Rickert, desde Baden-Baden, rehabilitando los estudios platónicos, hicieron ver la importancia del valor y la historia. Recomiendo, para una interpretación crítica de la lectura heideggeriana, el artículo de investigación de Moya (2004: 225-234).

2 Emplearemos para la citación de Kritik der reinen Vernunft (Kant, 1998). Antes del afamado y polémico Kant-Buch, Heidegger (1991) había impartido varios cursos sobre la obra magna kantiana: a) 1925-26. Logik. Die Frage nach der Wabrbeit (1976a: 269-416); b) 1927-28. Phenomenologische Interpretation von Kant KrV (1977). Ahora bien, el problema de la imaginación transcendental no es protagónico en la lectura de Heidegger sobre Kant, en ese ínterin producido en su vida entre la fecha de publicación de Sein und Zeit, en el año 1927, y el desarrollo del pensar de la "historia del ser" [Seinsgechichte], sino, yo diría, antes bien, que el problema capital, confluyendo con la posibilidad de constitución de una metafísica del Dasein como prueba explicativa del fundamento de la subjetividad (finitud), fue el problema de la libertad. Desde este prisma las siguientes obras heideggerianas son importantísimas: 1929.Vom Wesen des Grundes (1976b: 123-176); 1929/30. Die Grundbegriffe der Metaphysik (1983); 1931/31. Vom Wesen der Wabrheit (1976b: 177-202); 1936. Vom Wesen der Menschlichen Freibeit (1988a). Recomiendo, no obstante, la lectura de Vigo (2017: 123-159), sobre todo, a fin de obtener un desarrollo riguroso entre las relaciones de naturaleza y libertad, clave de lectura en la interpretación de Heidegger.

$3 \mathrm{Al}$ contrario que el Prof. José Eduardo Rivera (Heidegger, 2006), que traduce "temporalidad" por Temporalität y "temporeidad" por Zeitlichkeit, prefiero no atender a tal división, pues, en cualquier caso, ambos fenómenos, desde el plano de la obra cumbre heideggeriana, vienen a manifestar algo casi idéntico, sobre todo, si me ciño a una de las hipótesis vertidas en Sein und Zeit: el Dasein es el ente que trasluce y transparenta, de algún modo, el darse mismo del ser. No hay darse del ser si no pasa por el Dasein. Por tanto, ambos conceptos deben entenderse como horizontes de tiempo, esto es, en tanto temporalidad. Lo que sucede es que la palabra Temporalität tiene una finalidad trascendental, pues de lo que se trata es de ganar el horizonte general de presentación del ser del ente. Pero que no se olvide, este horizonte general, de presentación del ser del ente mismo, es la existencia, esto es, Dasein. 
Zeit ${ }^{4}$, una obra quebrada por inacabada en su proyecto integral, Heidegger había situado el rol de la temporalidad dentro de una explicación ligada al esquematismo, donde tal temporalidad, la temporalidad del Dasein como "ciudado" [Sorge], era la responsable del modo de configuración y ordenamiento de los éxtasis, los cuales quedaban abiertos en su irrupción en un "instante" [Augenblick], casi de rango kairológico, que se desplegaba como horizonte y sentido proyectivo, a fin de que aconteciera la temporalidad trascendental, valga decir: "la temporalidad del ser"6 [Temporalität des Seins], que, a su vez, se encargaba de dar cuenta, desde un aspecto global, como "en general" [überhaupt], del modo en el que el ente intramundano y el Dasein, en tanto ente señalado por una pre-comprensión singular de lo que "es", son abiertos y referenciados en un mundo, una época o una historia". Que tal horizonte relativo al ser en cuanto ser se posicione como trascendental no debe sorprender, en la medida en que no solo tiene que ver, stricto sensu, con las condiciones de posibilidad de las referencias hermenéuticas del ente intramundano y el Dasein, sino que, tal horizonte temporal, constituye un elemento que ha de quedar ínsito en toda modalidad referencial, o ejecutiva, propia de lo que hay, ejerciendo de factor constituyente sobre todo ente, justo lo que, en otras palabras, estibaba la noción de trascendental para Kant ${ }^{8}$.

$4 \quad$ Nos amparamos, para invocar el empleo de esta obra de Heidegger (2002), y de este modo hacer más fluida la lectura del texto, en la abreviatura $S u Z$.

$5 \quad$ Tal es la importancia del cuidado en (2002: 252): "El cuidado es el título ontológico para la totalidad del todo estructural del Dasein". [Sorge ist der ontologische Titel für die Ganzheit des Strukturganzen des Daseins]. Las traducciones de las obras de Heidegger son consideradas de mi responsabilidad. En la mayoría de los casos, cuando se considere menester, $\mathrm{y}$ atendiendo a la posibilidad de ofrecer al lector la oportunidad de contrastar y/o verificar la traducción llevada a cabo, junto con la traducción al español, irá parejo el texto en el original alemán.

6 Grosso modo, la meta de $S u Z$ radiacaba en la elaboración de un horizonte temporal, re-obtenido por mor de una hermenéutica de la "temporalidad" [Zeitlichkeit] mundana del Dasein, que sirviera como un "trascendental" desde el que comprender el ser del ente en general, en tanto temporalidad [Temporalität]. Este horizonte trascendental y temporal iba a ser expuesto en la III Sección que no ha sido publicada jamás, por mucho que se considere el curso del Semestre de verano de 1927 su continuación (1975).

Heidegger lo manifiesta en la Introducción a SuZ, único testimonio de un libro que, en su integridad sistemática, es inexistente: "aquello partir de lo cual en general el Dasein entiende e interpreta implícitamente algo así como el ser" [daß das, von wo aus Dasein uiberhaupt so etwas wie Sein unausdrücklich versteht und auslegt] (2002: 17).

8 "Llamo trascendental a todo conocimiento que se ocupa, no tanto de los objetos, sino de nuestro modo de conocerlos, en tanto que esto ha de ser posible a priori" [Ich nenne alle Erkenntnis transzendental, die sich nicht so wobl mit Gegenständen, sondern mit unserer Erkenntnisart von Gegenständen, so fern diese a priori möglich sein soll, überhaupt beschäftigt] (KrV A $11 / 12)$. 
Para no dar más rodeos con circunloquios, propios de una introducción infinita, la mirada curiosa de Heidegger sobre la obra de Kant principió en ver que los éxtasis, en su apertura como horizonte de mundo, respondían a un temple o "disposición afectiva" [Befindlichkeit] fundamental: la facticidad. Pero tal facticidad, se hacía reconocible, más allá de los caracteres heterónomos que pueda implicar su alusión al "yo soy sido" [ich bin gewesen], en su encarnación como finitud en un "estado de arrojamiento" [Geworfenheit]; o sea: el ordenamiento extático de los horizontes respondía a una temporalidad vivida como finitud, y esta finitud, se veía reflejada en la imaginación trascendental, en tanto poder productivo, configurador, que una síntesis peculiar ejerce sobre lo dado en la sensibilidad. Baste recordar: solo un ser finito puede ser afectado por la sensibilidad y, por ende, acarrear lo dado como otro desde un si-mismo'. Y como vengo diciendo, entre tanto, a pesar de la violencia exegética producida por Heidegger en su lectura de Kant, la vinculación de la imaginación a la temporalidad, como tiempo finito que asume lo que es y lo otro que no es, me parece sumamente fructífera. En primer lugar, porque tal lectura, en conformidad con la primera versión de $K r V$, logra un tipo de explicación que no separa, abismalmente, la apercepción trascendental, en tanto nexo a priori que enlaza y/o vincula todas mis representaciones ${ }^{10}$, y el tiempo, como sentido

9 De tal modo se pronuncia Heidegger (1977: 417-418), en un adelanto de lo que, desde páginas posteriores, se signará con el rótulo de "imaginación productiva" [produktive Einbildungskraft: "Pero si la imaginación productiva no es nada más que la más originaria unidad de los tres modos de síntesis, entonces, este poder ha ya esencialmente unificado, en sí mismo, la intuición pura y el pensamiento puro, la pura receptividad y la pura espontaneidad, o más exactamente, este poder es la raíz que las libera a ambas. La imaginación productiva es la raíz de las facultades de la subjetividad; es la extática constitución básica del sujeto, del Dasein mismo" [Wenn nun aber die produktive Einbildungskeraft in dieser Weise selbst nichts anderes ist als die ursprünglichste Einheit der drei Modi der Synthesis, dann hat sie schon ibrem Wesen nach reine Anschaunng und reines Denken, reine Rezeptivität und reine Spontaneität, in sich geeinigt oder ist, genauer gesagt, die Wurzel, die beide aus sich entläßt. Die produktive Einbildungskraft ist die Wurzel der Vermögen der Subjektivät, sie ist die elestatische Grundverfassung des Subjekts, des Daseins selbst].

10 “... el nuestro - el entendimiento- sólo puede pensar, y debe de buscar la intuición desde los sentidos. En relación, pues con la variedad que me ofrecen las representaciones en una intuición, tengo conciencia de la identidad del yo, ya que las llamo a todas representaciones mías, que forman, por tanto, una sola. Ello equivale a decir que tengo conciencia a priori de una ineludible síntesis originaria de apercepción. A esta unidad han de estar sometidas todas las representaciones que se me den, y a ella han de ser reducidas mediante una síntesis" [der unsere kann nur denken und muß in den Sinnen die Anschauung suchen. Ich bin mir also des identischen Selbst bewußt, in Ansehung des Mannigfaltigen der mir in einer Anschaunng gegebenen Vorstellungen, weil ich sie insgesamt meine V orstellungen nenne, die eine ausmachen. Das ist aber so viel, als, daß ich mir einer notwendigen Synthesis derselben a priori bewußt bin, welche die ursprüngliche synthetische Einheit der Apperzeption heißt, unter der alle mir gegebene Vorstellungen stehen, aber unter die sie auch durch eine Synthesis gebracht werden müssen] (KrV B135-136). 
interno puro, cuya funcionalidad más propia es posibilitar la sucesión de los contenidos sensibles ${ }^{11}$. En segundo lugar, la lectura que hace Heidegger, a pesar de la descontextualización ejercida sobre la inequívoca finalidad epistémica que tiene la obra kantiana -fundamentar un modo recto de conocimiento basado en la objetividad a fin de delimitar el conocimiento científico del metafísico-, es sumamente congruente y coherente, prima facie, con lo pensado por Kant, quien, de un modo bastante claro, emparentó la síntesis pura, producida por la imaginación trascendental, con el tiempo, y más concretamente con la modalidad de un tiempo que sabe de sí, siendo consciente de lo que es, denominado con el rótulo de "yo-pienso" [ich denke], pues, de lo contrario, ¿qué estamos afirmando: un ejercicio de espontaneidad, propio de la síntesis imaginativa sobre los contenidos sensibles, no temporal, a pesar de que tales contenidos se desplieguen en el tiempo? ¿Es ello, pues, una contradicción? Como se echa de ver, tal y como Kant mismo se encargará de explicar en la nueva concepción de la "Deducción Trascendental"" (KrV B 129-132), gestada en la segunda edición de la obra, es posible decir que no. Finalmente, la tentativa con visos de contradicción fue solventada relegando la función espontanea de la imaginación, en su vinculación con el tiempo, a favor del entendimiento, el cual, a partir de la segunda edición de $K r V$, oficiará de origen de toda síntesis, esto es, de otro modo: en la segunda edición, Kant desvía el modelo constitutivo que la apercepción trascendental tenía en la primera edición, la cual era vinculada con una finitud relativa al "ser-afectado" [bettrofen] del sujeto por la sensibilidad, desligándolo hacia un tiempo de carácter nouménico/noumenal, que no estaría sujeto a ningún tipo de coacción causal, como sí lo estaría, en cambio, la sensibilidad, en virtud de la segunda de las analogías de la experiencia $(K r V$ A 189-211/B232/256;

11 "Todo aumento del conocimiento empírico y todo avance de la percepción, cualesquiera que sean sus objetos -fenómenos o intuiciones puras-, no son otra cosa que un ampliar la determinación del sentido interno, es decir, un progreso en el tiempo" [Aller Zuwachs des empirischen Erlenntnisses, und jeder Fortschritt der Wabrnebmung ist nichts, als eine Erweiterung der Bestimmung des inneren Sinnes, d. i. ein Fortgang in der Zeit, die Gegenstände mögen sein, welche sie wollen, Erscheinungen oder reine Anschaunngen] (KrV A 210).

$12 \mathrm{Al}$ respecto, en esta segunda edición, el giro es bastante claro: “(...) la forma de tal intuición puede hallarse a priori en nuestra facultad de representación sin ser, a pesar de ello, otra cosa que el modo según el cual el sujeto es afectado. Pero la combinación (conjuctio) de una variedad en general nunca puede llegar a nosotros a través de los sentidos ni, por consiguiente, estar ya contenida, simultáneamente, en la forma pura de la intuición sensible" [(...) die Form dieser Anschaunng kann a priori in unserem Vorstellungsvermögen liegen, obne jedoch etwas anderes als die Art zu sein, wie das Subject affieirt wird Allein die Verbindung (conjuctio) eines Mannigfaltigen überhaupt kann niemals durch Sinne in uns kommen und kann also auch nicht in der reinen Form, der siinlichen Anschaunng zugleich mit enthalten sein] $(\operatorname{KrV} 129-130)$.

VERITAS, № 43 (agosto 2019) 
Heidegger, 1977: 141). De este modo, entonces, la imaginación, además de relegada y marginada, fue reducida a una función de síntesis empírica e impotente con lo importante: la constitución trascendental de toda experiencia.

En lo que sigue, trataré de repensar, dentro de la intuición marcada por Heidegger, el papel que juega la noción de imaginación trascendental, en su vinculación inexorable, por un lado, con la apercepción trascendental, y con el tiempo, por otro, a fin de alcanzar, al menos, un esbozo temático de tal imaginación en términos de auto-afección radical del sí-mismo ${ }^{13}$.

\section{SENSIBILIDAD Y AFECCIÓN: PRIMERA FORMA DE CONOCIMIENTO}

Creo que en la interpretación de Heidegger convergen elementos de lectura sumamente productivos, los cuales rehabilitan un ámbito del pensamiento que, a lo largo de la historia de la filosofía, han sido omitidos y

13 Como se viene manifestando, la investigación ejercida constituye, quizá, una tarea pendiente en la propia lectura que Heidegger realiza sobre Kant, desde prácticamente 1925, cuando era docente en Marburgo (Heidegger, 1977: 1976a). Esta interpretación realizada por Heidegger sobre Kant es enmarcada dentro de una lectura, profunda y pormenorizada, de la Crítica de la Razón Pura, no exenta de riesgos exegéticos (véase nota 1). En este sentido, Heidegger estima que Kant huye y rechaza su descubrimiento más productivo: que el fundamento de la subjetividad se juega en el ámbito de la imaginación trascendental (Atger, 2006; Rodríguez, 2006). Esto habría permitido que Kant hubiese expandido la noción de subjetividad, habiéndola comprendido como un modo ligado inexorablemente a la temporalidad. El coste de este rechazo habría sido letal, instaurando un hiato incomunicable entre la apercepción trascendental — que enlaza a priori lo múltiple en representaciones dadas - y el tiempo - sentido interno por donde se suceden los contenidos sensibles- (Torretti, 2005: 563). Heidegger habría pensado que ambos momentos, el ligado a la apercepción y el otro relacionado con el tiempo, no estarían desconectados, sino comprometidos uno en el otro, dando una explicación plausible sobre la génesis de lo categorial (Ainbinder, 2011: 5), y posibilitando una explicación más holista, radical, del estatuto de la subjetividad, sobre todo en el rol que ésta juega dentro del dominio constitutivo de toda experiencia (Durán, 2005: 54-64). De este modo, la génesis constitutiva de la experiencia no se juega, solo y en exclusividad, dentro de los dominios categoriales, sino de una peculiar síntesis, emanada de la temporalidad de la propia instancia subjetiva, es decir, el sujeto de carne y hueso, el sujeto afectado, el sujeto que imagina, padece y siente, el sujeto que se vive como una temporalidad auto-afectiva, la cual, según la interpretación que espero mostrar en adelante, debe entenderse como una peculiar manera de "mismidad" [Selsbtheit] propia y singular del Dasein, alejada de determinaciones substanciales, que hagan del sí-mismo una experiencia tramitada por las formas de objetividad y representación, del yo como subiectum, y no, más bien, una forma que emerja desde un encontrarse existiendo, abierto afectivamente a mundo, teniendo, en cada caso, que lograr una apropiación sobre lo sido. Esta última forma de encaje sobre el fenómeno de la mismidad supondrá el hilo narrativo, conductor, de la investigación aquí llevada a cabo. 
soterrados: los elementos no-apofánticos del pensamiento, esto es, toda modalidad de pensamiento no acogido por el logos apophantikos, en su afirmación como enunciado y en su determinación como predicación (Garrido-Periñán, 2019a). Dicho de modo positivo, el tratamiento heideggeriano posibilita un tratamiento trascendental de la experiencia (existencial) en su modalidad pre-categorial, haciéndola depender de un modelo de explicitación temporal en relación con la síntesis pura, que encuentra su sede en el mismo sujeto, que se ve, a sí mismo, temporalizado como finitud radical ${ }^{14}$ (Zuckerd, 2007: 216). Ahora bien, esta sede, anclada en el sujeto, en este nivel de análisis, no tiene nada que ver con un tipo de subjetividad sofisticada, curtida en la duda metódica idiosincrática del ego cogito; antes bien, el sujeto aquí esbozado, que deja ver el concurso de la imaginación trascendental sobre la síntesis del tiempo, es un sujeto dado como modo primario de una temporalidad de carácter afectivo, la cual no solo es afectada por el contenido dado en la sensibilidad como intuitus derivativus, sino que sabe de sí, es auto-afección inmanente, un cierto tipo peculiar de "mismidad"15 [Selbstbeit] (Garrido-Periñán, 2018: 150-170), expresada por Kant, aunque ahora de modo muy provisorio, por el yo-pienso que acompaña a todas mis representaciones (1998: B132; Heidegger, 1976a: 271). Nótese la hechura de esta última afirmación: si la síntesis pura, emanada de la imaginación, unifica la multiplicidad acontecida en la sensibilidad, y esta unificación sintética es vivida, dada o acontecida como auto-afección en el sujeto, cualquier concurso de mediación categorial de carácter lógico, es, al menos, secundario, es decir, que el entendimiento, como facultad que provee conceptos

14 En sintonía con los expresado por Rachel Zuckert (2007: 215-231), la explicitación de una síntesis - junto al yo-pienso que oficia de centrum y unidad de tal acto sintéticocomo separada del tiempo acarrea muchos problemas, más allá de la acusación de un cartesianismo residual por parte de Kant. Lo importante aquí, entre otras cosas, es la señalización meridiana de que habría un reconocimiento trascendental de la experiencia que no dependería, en exclusividad, de principios categoriales, ligados al rendimiento de la actividad propia del entendimiento, sino que serían deudores, siguiendo a Kant, del propio sujeto-trascendental, quien efectuaría tal síntesis, o, para decirlo con Heidegger: por la temporalidad originaria, en su capacidad imaginativa, la cual emerge de la finitud de la existencia.

15 El sí-mismo, o la mismidad, apunta a un fenómeno temporal en las dimensiones prácticas del mundo entorno, mundo compartido y, por último, mundo de sí mismo (Heidegger, 1988a: 176; 1995: 11, 13, 103, 187-188, 192, 204, 211, 212-214, 227-228, 228 , 232, 237-241, 245-247, 253-255, 298, 331-332; 1992: 54-58, 54-58, 342, 348, 440-441, 442; 1988b: 29 y 102; 1976b: 236, 338-344, 344-347 y 1975: 194, 224-228, 242, 249, 394395 422, 425). No hay que olvidar que la analítica existencial, propedéutica para alcanzar el horizonte de aprensión de la "Temporalidad del ser" [Temporalität des Seins], pasaba, si y solo si, por un análisis de las estructuras existenciales del ente que se pregunta por el ser, el Dasein (supra., nota 3). 
a intuiciones mediadas por el juicio, no ostenta el monopolio del conocimiento $^{16}$. La sensibilidad es, per se, una primera forma ante-predicativa de conocer el mundo, la cual es dada como un ser-afectado de carácter autorreferencial, es decir, como auto-afección. Huelga decir, por lo demás, que tal afirmación no le resta ni un ápice a la labor esencial que juega el entendimiento en la génesis de conocimiento de carácter cognitivo, sino que, en mi opinión, la amplía, favoreciendo tipos de modalidades de conocimiento que deben ser reconocidas en tanto tienen su suelo fundamental en las disposiciones afectivas ${ }^{17}$.

El carácter de la afección bajo el prefijo auto-, como se echa de ver, no presenta tan solo un carácter de epíteto secundario, significa que no hay intuición solamente latente o pasiva, sino que en la capacidad de intuición, para el ser humano, se juega un factor activo, el cual tendría que ver con la pre-posición de la formación de un ámbito de recepción de lo sensible, justamente, para que algo que es dado encuentre un tipo de correspondencia o vinculación ${ }^{18}$ (Heidegger, 1976a: 73-74). Esto equivale a manifestar que toda intuición derivativa, propia del ser humano, tenga que ser pensada como una capacidad formativa, de producción y/o "formación" [Herausbildung] por la que algo "viene a presencia" [in-die-Anwesenheit-kommen],

16 Esto hubiera sido una negación en sus propios términos de la $K r V$, pues la razón, como facultad señorial y pura, no hubiera podido dar cuenta del edificio sistemático del saber.

17 Recomiendo la lectura de Robson Dos Reis (2018: 121-142), quien realiza, a mi modo de ver, un excelente intento de reconstrucción, de carácter fenomenológico y genético, sobre la cuestión relativa al conocimiento teorético, propio de las ciencias llamadas positivas, y su vinculación con las formas de conocimiento denominadas por Heidegger como pre-reflexivas, las cuales quedan referenciadas ejecutivamente en la nuda facticidad de la existencia.

18 En este sentido, en $S u Z$, Heidegger emplea dos términos sumamente importantes en el momento que quiere dar cuenta de la formación del Um-Welt: "poner/quedar en libertad" [freigeben/Freigabe] y "ser-libre" [Freisein], los cuales, dentro de un tratamiento aleteiológico de la verdad (Vigo, 2010: 161-181), se emplean con la finalidad de dar cuenta sobre qué modo se produce la vinculación del agente de experiencia, denominado Dasein, con su mundo circundante, dentro de un contexto de pragmaticidad de carácter holístico, cuyo origen es el "trato práctico" [Umgang]. La conclusión, grosso modo, es que el Dasein deja en libertad al ente intramundano porque permite su vinculación a horizontes significativos, los cuales, paradójicamente, son él mismo Dasein (Crowell, 2018: 227-254), en la medida en que todo "para qué" [Um-₹u], que regula la utilidad pragmática del "útil" [Zeug], es dependiente y deudor de un "por-mor-de" [Worum-willen], desplegado en exclusividad por este ente denominado Dasein, como modo anticipativo y autorreferencial de su ser. Me permito la citación (Garrido-Periñán, 2019b), donde doy buena cuenta de cómo se produce este modelo constitutivo del útil basado en la noción de libertad y el modelo original de verdad presentado por Heidegger, en las modalidades de: "serdescubierto" [Entdecktheit], "ser-descubridor" [Entdeckend-sein] y "estado de apertura" [Erschlossenheit]. 
para decirlo con Heidegger; o "es dado" [es ist gegeben], sin más, para decirlo con Kant.

En mi opinión, siguiendo este hilo conductor, esta interpretación vendría a hacer justicia al descubrimiento kantiano sobre la determinación del tiempo como algo subjetivo, en tanto intuición interna a priori de la sensibilidad. Por esta razón, aunque la interpretación exegética de Heidegger sea interesada y sesgada, en la medida en que no solo olvida la edición segunda de la $\mathrm{KrV}$, sino toda una amalgama de textos kantianos donde el propio Kant intenta responder a tal problemática ${ }^{19}$, paradojalmente se reviste de cierta importancia, en la medida en que su interpretación consigue abrir un nexo con el tiempo, logrando una determinación sobre éste en tanto disposición afectiva que revela una primera modalidad de conocimiento, siempre y cuando se atienda a que el tiempo es una afección que deja ver o "echar una mirada" [Hinblicknahme], conformándolo, dotándole de una "imagen" [Bild], a aquello que es dado en la sensibilidad. Este sería, según Heidegger, la primera forma en la que se manifiesta la unidad sintética de lo que es dado, esto es, como tiempo en su carácter de disposición afectiva:

La unidad sintética original de la auto-conciencia es, primero, la unidad original que permite la síntesis; segundo, la síntesis original que permite la unidad. Lo segundo está constitutivamente contenido en lo primero. A la síntesis le pertenece el ponser-se-a-sí-mismo-en-su-mismidad del yo, o sea del yo que piensa, que representa algo ${ }^{20}$.

\section{TEMPORALIDAD: AUTO-AFECCIÓN DEL SÍ-MISMO Y EL CARÁCTER CON- FIGURADOR DE LA IMAGINACIÓN}

Por lo demás, la interpretación de Heidegger sobre Kant no dista de las diversas interpretaciones que ejerció sobre otros filósofos, sobre todo en el modo de tratar el aspecto crítico de tal interpretación: la acusación heideggeriana estribaba en designar a los filósofos de la historia de la filosofía, a pesar de su hondura en algunos casos, como faltos de una adecuada comprensión del tiempo, por la que concepciones del tiempo como algo

19 Estos textos son, al menos, los siguientes: Kritik derpraktischen Vernunft (Kant, 2003); Kritik der Urteilkraft (Kant, 2001a); Logik. Ein Handbuch zu Vorlesungen (Kant, 1920: 1-150, 503-508) y Prolegomena (Kant, 2001b).

20 Heidegger (1976a: 325-326): "Die ursprüngliche synthetische Einheit des Señbstbewußtsein ist 1. die ursprüngliche Einheit ermöglichende Synthesis 2. Urprüngliche Synthesis ermöglichende Einheit. Das Zweite ist im Ersten knostitutiv enthalten. Zur Synthesis gehört das Sich-selbst-in-seiner-Selbigkeit-Setzen des Ich, und zwar des Ich, das denkt, etwas vorstellt". 
que se determina en un ahora o un puctum concreto $^{21}$, además de cortas, eran insuficientes, siempre y cuando se quiera comprender la singular esencia finita del ente que se pregunta por el ser: el Dasein. Pero, como vengo diciendo, no es lugar este para ajusticiar la mala praxis exegética de Heidegger, muy criticada por lo demás, sino, más bien, esforzarse para hacer valer la intuición de que el tiempo, en tanto forma pura de la intuición, el cual revela, en último término, un ser-afectado vivido como autoafección, no es tan solo un estado de ánimo más, al modo de lo que recoge las palabras latinas mes o animus, o la palabra alemana, empleada por Kant: Gemüt. El ánimo es subjetivo no solo por su contraposición con lo objetivo o externo -el espacio- ${ }^{22}$, sino porque revela la estructura singular del tiempo cuando es vivido en una existencia como la humana que ha de enfrentar, sin posibilidad de abdicación, su finitud. Esto implica que el tiempo no sea, en exclusividad, un estado de ánimo más, un ser-afectado sin ton ni son, sino que es la primera y germinal forma del ser del si-mismo. Y ello más allá de la afirmación de un aspecto activo en la recepción de la sensibilidad: esta temporalidad finita, la cual cobra hechura porque la muerte nunca es un hecho consumado para el ser humano - sino un modo de relación que temporiza lo que somos- vivida como auto-afección, constituye la síntesis original que permite que lo intuido sea, estrictamente, intuido como algo y que, a su vez, en ese algo intuido se refleje lo que somos, esto

21 La definición más idiosincrática la dio Aristóteles, quien define el tiempo como el numero del movimiento que acontece desde el horizonte de lo anterior y posterior (Física IV, 11, 220a 25).

22 Por supuesto, el espacio, en tanto intuición pura y externa de la sensibilidad, jugaría un importante rol en la constitución de esta auto-afección propia del sí-mismo, en la medida en que la experiencia espacial permitiría la posibilidad de la simultaneidad de la sucesión dada en el tiempo. Por ende, a través de la experiencia espacial, en cuanto determinación externa, sería posible que cobrara cierta hechura fenoménica lo que, desde la conciencia interna del tiempo, se presenta como unidad "aperceptiva" de mi yo-pienso, encarnado en un cuerpo. En este sentido, el artículo de Claudia Jáuregui (2011: 31-47) es altamente revelador. Ahora bien, y del mismo modo, en este artículo la autora se expresa en términos tajantes: "La experiencia interna no es más que una abstracción..." (2011: 47). Y esto lo manifiesta porque sostiene la interpretación de que, desde el sentido interno -el tiempo-, no es posible la conjunción de una experiencia de carácter cognitivo, esto es, que pueda ser objetivada. De alguna manera, aunque no sea la intención primordial, el escrito que presento viene a responder a la posibilidad de enmarcar una experiencia pre-reflexiva, denominada auto-afección, la cual es deudora de lo que se da, o aparece, en la intuición pura del tiempo, haciendo, a la par, posible tal experiencia interna, desmarcándola de manifestaciones de tan tajante calado, sobre la imposibilidad cognitiva de tal experiencia interna signada como tiempo, $y$, por ende, no estaría de acuerdo con parte de las conclusiones extraídas por Jáuregui. 
es, un modo en el que el Dasein queda abierto qua Dasein ${ }^{23}$, en contraposición con el modo de ser del ente intramundano. Esta es, a mi juicio, como vengo diciendo en otras publicaciones (Garrido-Periñán, 2019a; 2019b; 2018: 150-174; 2017: 158-182), la primera forma de constitución de la mismidad del Dasein. Por esta razón, se permite decir Heidegger, en mi opinión, lúcidamente, que, en esta síntesis emanada del tiempo, en tanto intuición a priori y pura de la sensibilidad, no entra a concursar objeto alguno: "El previo dejarse-dar algo -atemáticamente- es el tiempo, y lo que el dejarse-dar se da es el tiempo, es decir, el sujeto se afecta consigo mismo" [Das vorgängige Sichgebenlassen - unthematisch - ist Zeit und das, was das Sichgebenlassen sich gibt ist Zeit, d.h. das Subjekt affiziert sich mit ihm selbst] (1976a: 341). O sea, la imaginación, desde este lado, se encarga de la pre-configuración del horizonte extático, que regula toda posibilidad de conocimiento, sea categorial, o no; o mejor, en términos kantianos: la imaginación se encargaría de pre-figurar el modo en el que los esquemas han de ser ordenados, esquemas cuya función primordial es la configuración de las categorías, las cuales dan cuenta del modo en que se ordena la realidad, propiciando lo que sería unas de las metas más importantes para Kant: alcanzar, de intuiciones ciegas, referencias objetivas, que den cuenta de la realidad.

De este modo, creo que se puede decir que la imaginación, como facultad original de enlace y síntesis sobre la sensibilidad, proporciona una primera atestiguación del sí-mismo dado como auto-afección, en una suerte de hechura no-objetual. Esta morfología del sí-mismo como noobjetual tiene que darse como una proto-imagen, la cual, siguiendo a Kant, debe ser traslada al decurso de la teoría del esquematismo y su vinculación con la génesis categorial. Pues bien, la imaginación entra a concursar en el sistema epistémico kantiano por cuanto participa en la ordenación dada en los esquemas trascendentales, determinados, a su vez, en tanto temporalidad. En este sentido, los esquemas trascendentales proveen una protoimagen y/o "aspecto" [Aussehen] por sobre aquello que es dado, oficiando de regla de todo acto de "presentabilidad". Tal aspecto se cifra en que lo dado siempre lo hace bajo unos criterios, a saber: perdurabilidad, sucesión y realidad (Heidegger, 1976a: 321). Ahora bien, el sí-mismo, como expresión radical de la temporalidad finita que regula todo acto relativo a la imaginación trascendental, viene a cubrir un ámbito de respuesta ante una pregunta que, de cierto modo, pudo motivar la reformulación de la imaginación, en su rol constituyente, impuesto por Kant en la segunda edición de $K r V:$ ¿desde dónde vienen los aspectos o proto-imágenes que ofician

23 A fin de poder extender una conexión, a mi juicio importantísima, entre este estado de apertura, signado como mismidad, y el fenómeno eminente de la "verdad de la existencia" [Wabrheit der Existenz], recomiendo la lectura de: Heidegger (2002: 221).

VERITAS, № 43 (agosto 2019) 
de ingredientes de todo acto imaginativo? ¿de dónde saca la imaginación sus productos? Es aquí donde cobra sentido el epíteto trascendental sobre la imaginación: la imaginación se da a sí-misma su (proto)imagen sin necesidad de que concurse lo empírico de por medio, y haciendo esto, además, posibilita la inteligibilidad de todo acto cognitivo. De este modo, cumple su función de elemento trascendental, dentro de la obra kantiana, pues no da cuenta del contenido de la experiencia solamente, sino de la manera en la que ésta se constituye. Se hace, además, siguiendo la estela de esta explicación, justicia a la expresión cotidiana a través de la cual se documenta la significación de la expresión "imaginación", radicada en una facultad que hacer ver cosas, sean ideales o no, sin necesidad de que se den, stricto sensu, en la experiencia. Imaginación es, entonces, la posibilidad de un ver no-mediado por su referencia objetiva u objetual. Su "fuerza configuradora" [bildende Kraft], auspiciada como temporalidad respectiva de un ser finito, provee una imagen, forma, "a la vez" 24 [zumal] pasiva y activamente, pues siempre ya recibe, en su ser-afectado (recepción), y crea, sintetizando espontáneamente tal multiplicidad recibida por la sensibilidad, por la cual lo afectado es afectado como tal (Heidegger, 1991: 129). En este aspecto activo, en el que la imaginación sintetiza y ordena lo recibido y/o afectado, una concepción del tiempo está emergiendo. Este tiempo emergente, como se ha dicho ya, es el tiempo de la "existencia" [Existeng], o sea, una temporalidad finita, la cual dista de toda caracterización categorial que se haga sobre ella, subsumiéndola en una suerte de serie de sucesión, sea de orientación causal, o no. Lo importante aquí es que el tiempo finito surge a partir del momento activo, sintético, perteneciente a la imaginación. Esto significa que el tiempo finito aparece como una suerte de intuición noobjetiva, de carácter a-temático y ante-predicativo, el cual tiene que ver, principalmente, con la constitución de la condición de posibilidad de que algo dado pueda salir al encuentro, sea presente, y, a posteriori, pueda ser enlazado juticativa-categorialmente. Ahora bien, esta función constituyente, como se echa de ver, para ser explicada con propiedad, sería menester, antes, realizar una vinculación explicativa con el problema del esquematismo y las categorías, a fin de poder considerar con propiedad qué aporte tendría la incorporación de la sensibilidad, con todo este background abierto por la imaginación, en las formas de juicio con alcance cognitivo.

24 Siendo una facultad que no está destinada a la presencia de lo intuible, realiza ella misma, es decir, crea y forma la imagen. Esta fuerza configuradora es un formar a la vez pasivo (receptor) y creador (espontáneo). En este a la vez se encuentra la propia esencia de su estructura [Als sein auf Anwesenheit des Anschaubaren nicht angeweisenes Vermögen vollzieht sie selbst, d. h. schafft und bildet sie das Bild. Diese "bildende Kraft" ist zuman ein binnehmendes (rezeptives) und ein schaffendes (spontanes) "Bilden. In diesem "zu mal" liegt das eigentliche Wesen ibrer Struktur] (Heidegger, 1991: 128). 
Pero tal tentativa, por el momento no puede ser abordada en aras de una concentración analítica de la propia temporalidad finita abierta desde y con el acto imaginativo. Si esta temporalidad finita es finita porque recibe de otra parte lo dado, esto es, su ser-afectado adviene porque para ser, y constituirse, necesita de otra cosa que no es ella misma para ser, tal temporalidad, al socaire de la actividad sintética y espontánea que la imaginación tiene para Kant, no es dada, en exclusividad, como un ser-afectado, sino que es "a la vez/en una" [zumal/in einem] formadora, creadora, es decir, la temporalidad finita, emanada de la imaginación trascendental, no es otra cosa que auto-afección, la cual permite no solo que lo heterónomo y/o recibido pueda ser articulado en un tipo de afección como es la respectiva del tiempo finito de la existencia, sino, además, que tal fenómeno pueda comprenderse como unitario ${ }^{25}$.

\section{LA APARICIÓN DEL SÍ-MISMO/MISMIDAD: RE-SIGNIFICADOR DE LA TEM-} PORALIDAD

De la posibilidad de esta unidad, dada como temporalidad finita, se encarga el vínculo que a principio del artículo de investigación mencioné entre el tiempo y el yo-pienso. Pues bien, si lo característico del acto imaginativo por excelencia es el ser-afectado por algo que no se da en la experiencia empírica, en tanto cosa u objeto ${ }^{26}$, ¿qué es lo que realmente es

25 Así de tajante se expresa Heidegger (1991: 175-176): "Pero esta serie de ahoras no es, de ninguna manera, el tiempo en su originariedad. La imaginación trascendental, por el contrario, permite que el tiempo como serie de ahoras brote, y, por ende, como esto que deja-brotar, es el tiempo originario" [Diese Jetztfolge ist aber keineswegs die Zeit in ihrer Ursprünglichkeit. Die transzendentale Einbildungskraft vielmehr läßt die Zeit als Jetztfolge entspringen und ist deshalb -als diese entspringenlassende - die ursprüngliche Zeit].

26 Gegenstand es unas de las traducciones al español de objeto, el cual puede ser traducido, del mismo modo, por Objekt. Desde diferentes perspectivas, hay quienes sostienen su tajante división (Caygill, 2000: 317), considerándola importantísima para la matriz filosófica de la filosofía trascendental kantiana, siendo Gegenstände objetos de la experiencia en su sentido lato, mientras que Objekt es el objeto de la experiencia en un sentido restringido, o sea, como objeto relativo al entendimiento. Ahora bien, como digo, hay controversia, Pedro Ribas, uno de los traductores al español de $K r V$ (Kant, 2005: $\mathrm{XXV}$ ), según parece, desestima la diferenciación, al pensarla de poco importante; también lo hacen Förster y Rosen (Kant, 1993: 49), traductores al inglés del Opus Postumun kantiano. Heidegger, a mi parecer, a lo largo de su interpretación, mantiene tal división, entendida en términos ontológicos, en virtud, precisamente, del aporte que lo trascendental tendría sobre la misma experiencia, haciéndola depender de criterios logicistas, es decir, pensado el objeto como Objekt, o correlato lógico de la unidad de apercepción, en presunto divorcio con la intuición sensible, a la que estaría, irremediablemente, emparentada la noción germana Gegenstand. Como se ha mostrado ya (supra, nota 1), Heidegger es muy crítico con esta interpretación. Nótese, además, que, en 
dado desde la imaginación? Si, desde otro lado, aquello por lo que soy afectado, a través de la imaginación, no es un objeto, una cosa que estáahí, en el mundo, a mi alrededor, entonces, ¿qué es? Lo que es dado, por decirlo así, brutamente sin-objeto, en respectividad al acto imaginativo, es un modo de "encontrar-se" [befinden-sich] y, por ende, de recepción, el cual formaliza y pre-configura la posibilidad de todo posible encuentro con el ente, o de otro modo menos heideggeriano: de todo posible acto de conocimiento. Esto que pre-configura es la propia finitud, la cual presenta, en relación con la temporalidad netamente imaginativa, una hechura circular, en la medida, tal y como sucedía con el problema relativo a la circularidad hermenéutica, en que esta finitud no crea nada, sino que resignifica o reformaliza aquello que siempre ya es dado. Y esta re-significación de lo dado, temporalizada en el modo de presentación de la finitud, y a juicio de Heidegger, Kant ha situado, en principio, al yo-pienso (Heidegger, 1976a: 404-408), como se sabe, una estructura refractaria a cualquier subsunción objetual o representacional. El yo-pienso es un yo que acompaña a mis representaciones, pero no es él mismo una representación.

Se puede comprender, espero, ahora mejor el porqué lo abierto a través del fenómeno de la temporalidad originaria de la imaginación, vivida como auto-afección, es una forma que tiene que denominarse como símismo y/o mismidad, pues su importancia capital no estriba, solamente, en otorgar un tipo de explicación genética sobre el proceso de formación categorial de los juicios objetivos, en la medida en que éstos remiten a horizontes ante-predicativos, sino, más bien, porque lo que deja ver, como huella, el acto espontáneo de la imaginación, entendido como bildende Kraft, es la manera, nítida y clara, por lo que lo más propio del ente, que en cada caso somos nosotros mismos, se presenta y es dado, esto es, como una temporalidad finita que "ha de ser" [zu-sein] y "asumirse" [Übernehmen-sich], en cada caso, siempre ya, tal y como, en una obra como SuZ, Heidegger caracteriza la singularidad existencial del $\operatorname{Dasein}^{27}$. Como se observa, la apelación a un sí-mismo, en relación con el Dasein, valga decir, cada uno de nosotros, no tiene nada que ver con un "carácter cósico" [Dinghaftigkeit] de ser, ni siquiera el yo implícito que pudiera rastrearse bajo la expresión

lo que queda de artículo de investigación, me moveré, a fin de expresar el desarrollo exponencial que la imaginación tiene sobre la constitución del objeto de la experiencia, de tal ambigüedad temática, entre Gegenstand y Objekt.

27 Para Heidegger, el carácter existencial que porta el Dasein se ve recogido en los existenciarios: "tener- que-ser" [zu-sein] y "ser-en-cada-caso-mío" [Jemeinigkeit]. "Existencialidad" significa portar la marca que implica el hecho fáctico de "tener-queser", en este mundo, y que las referencias ejecutivas, implícitas en el hecho de ser, se vuelvan contra mí, imprecándome a tener que decidir, en unas decisiones en la que queda en juego la misma existencia, mi existencia (Heidegger, 2002: \9). 
sí-mismo actuaría aquí como un puctum, o como polo unificador de la experiencia. El nivel de análisis presentado aquí es más primitivo, ya que intenta hacer ver que el tiempo, como intuición interna y pura, solo es posible si se lo piensa como auto-afección, es decir, como una afección de corte autorreferencial, la cual, a pesar de ser pasiva, por cuanto recibe lo dado de la experiencia, siempre tiene que asumir eso dado bajo un horizonte y/o "proyecto" [Entwurf], permitiendo así el despliegue del tiempo como temporalidad ${ }^{28}$. La explicación de Heidegger, en este punto, se nutre de la señalización kantiana en referencia al tiempo como una intuición pura e interna, ligada al yo-pienso, pero la transforma, como es sabido, por un tipo de explicación trascendental, la cual presenta al tiempo como posibilidad extática que da cuenta del modo en que se abren los horizontes por lo que todo ente puede ser presentado $\mathrm{y}$, por ende, inteligido y/o comprendido. Pero tal explicitación discursiva y trascendental sobre el tiempo, ensayada con protagonismo en SuZ (también Heidegger, 1975; 1991), en mi opinión, no le hace justicia a la primeriza caracterización kantiana. Que tiempo remita al sí-mismo significa que tal sí-mismo, como manera autorreferencial por la que la impronta de nuestro ser sale a relucir, actúa como re-formulador, re-temporizador del modo en que la temporalidad ha de quedar abierta y desplegada en cuanto tal. Y esto a pesar de que el símismo recibe de la temporalidad la posibilidad de su constitución, en la medida en que tal sí-mismo aparece, desde esta caracterización primaria, como un modo de "disposición afectiva" [Befindlichkeit].

\section{CONCLUSIONES}

Así, de este modo, creo que se hace plausible unos de los ejes de lectura heideggeriana sobre Kant, en tanto se preguntaba si, a partir del problema kantiano, formulado en la primera edición de $K r V$, se podrían hallar las bases para una metafísica del Dasein, esto es, una explicación sobre el

28 Empleo el término temporalidad, ahora, desde un sentido general, en tanto tiempo mío, tiempo relativo a la existencia. En estos términos, se expresa Heidegger: "El tiempo como afección pura de sí mismo no es una afección efectiva, que alcance a un sí-mismo ante los ojos, sino que, siendo pura, forma la esencia de un concernirse-a-sí-mismo" [Die Zeit ist als reine Selbstaffektion nicht eine wirkende Affektion, die ein vorhandenes Selbst trifft, sondern als reine bildet sie das Wesen von so etwas wie Sich-selbst-angehen] (1991: 189). La temporalidad es, por ende, un tiempo del concernirse-a-sí-mismo, de ribetes autorreferenciales y, en cada caso, mía.

29 Muy brevemente, si el sí-mismo se diera a sí su propia constitución, estaríamos hablando de un idealismo y de un principio de autodeterminación. No es el camino que sigue Heidegger en su propuesta filosófica. 
fundamento de la subjetividad. Se entiende, pues, que el tiempo sea producto de fundamentación de la subjetividad finita de la existencia, pero, entre tanto, si y solo si tal temporalidad logra ser vinculada con el símismo, en tanto modalidad autorreferencial sobre la afección temporal, que se encargaría de todo posible acto re-significativo sobre lo dado en toda temporalidad. Solo cuando el tiempo, acontecido como una afección de carácter heterónomo, es abierto y asumido en el proyecto de una temporalidad finita como la nuestra, que, además de desplegarse en un tiempo contingente, siempre ha de asumirse y constituirse sobre toda posibilidad, es posible hablar, en rigor, de un sí-mismo. En SuZ, tal modalidad eminente de asumir el proyecto arrojado de la existencia fue signado como "el sí-mismo propio" 30 [eigene Selbst] y, en el modo de su constitución, como "estabilidad del sí-mismo"31 [Selbständigkeit]. Tales explicaciones, que quedaron un poco desdibujadas por la finalidad ontológica impuesta por Heidegger sobre su opus magnum, a mi juicio, encuentran, desde su estudio de Kant, en concreto por la relación habiente entre tiempo, yo-pienso e imaginación, una explicación que atiende a la pregunta por el origen constitutivo de tal sí-mismo, el cual había oficiado de existenciario indispensable para entender el desarrollo de otros tales como: "por-mor-de" [Worumwillen], la "angustia" [Angst], el "ser-para(vuelto-a)-la-muerte" [sein-zum-Tode] o el "llamado a la conciencia" [Ruf des Gewissens], entre otros.

Esta posibilidad, la de re-direccionar el modo de apertura de la temporalidad originaria y auto-afectante, sobre la base de la mismidad, y en la medida en que se piensa a esta última, como impronta afectiva-comprensiva por la que lo más propio e idiosincrático del modo de ser del Dasein sale a relucir, o sea, no tan solo desde su determinación brutal como finitud, sino como proyecto que, siempre ya, aunque sea de manera arrojada, debe asumirse, sostenerse, emprender una vida, a mi juicio, permitiría una nueva lectura de esta parte de la obra de Heidegger previa a lo que se ha

30 De manera casi enunciativa, a modo de titular y en contraposición con la forma alienada propia del das Man, es caracterizado el sí-mismo-propio, a saber: "Perdido en la opinión pública del uno y en su habladuría, el Dasein, al escuchar al uno-mismo, pasa por alto su propio sí-mismo" [Sich verlierend in die Öffentlichkeit des Man und sein Gerede überhört es im Hören auf das Man-selbst das eigene Selbst] (2002: 271).

31 Así queda enunciada tal estabilidad relativa al sí-mismo: "La estabilidad del sí-mismo no significa existencialmente otra cosa que la resolución precursora. La estructura ontológica de la resolución precursora revela la existencialidad de la mismidad del sí-mismo" [Die Selbst-sta "ndigkeit bedeutet existenzial nichts anderes als die vorlaufende Entschlossenheit. Die ontologische Struktur dieser enthu "llt die Existenzialita "t der Selbstheit des Selbst]. Seguimos la traducción de J. Rivera (2006: 322). 
denominado Kehre ${ }^{32}$. Haciendo justicia, quizás, sobre la injusticia de la interpretación que el mismo Heidegger, con harta frecuencia, llevó a cabo sobre otros pensadores y filósofos. O sea, la lectura con sede en la mismidad, como momento articulador y ejecutivo de toda temporalidad de carácter finito, podría otorgar una posibilidad de nuevos horizontes interpretativos sobre la obra heideggeriana. Y en esta apertura al ámbito de nuevos horizontes interpretativos, activar lo no-dicho por Heidegger, a fin de que sea posible pensar por sí mismo.

\section{REFERENCIAS}

Ainbinder, B. (2011). Introducción. De la filosofía trascendental a la ontología fundamental. En: B. Ainbinder (ed.), Studia Heideggeriana 1: Heidegger-Kant (pp. 9-23). Buenos Aires: Teseo.

Aristóteles. (2002). Física. (G. R. De Echendía, Trad.). Madrid: Gredos.

Atger, P. E. (2006). Phénomène, schème, figure. L'origine de l'ontologie figurale de Heidegger. Les Études Philosophiques, 76(1), 29-46.

Caygill, H. (2000). A Kant dictionary. Oxford-Massachusetts: Blackwell.

Crowell, S. (2018). Heidegger acerca del razonamiento práctico: moralidad y agencia. En R. Rodríguez (ed.), Guía Comares de Heidegger (pp. 227-254). Granada: Editorial Comares.

Durán, C. (2015). La auto-afección del otro: Heidegger y el tiempo que demora el sí-mismo. Revista de Filosofia, 71, 53-64.

Fräntzki, E. (1985). Kehre. Heideggers Schrift Vom Wesen der Wabrbeit: Urfassungen und Druckfassungen. Pfaffenweiler: Centaurus-Verlagsgesellschaft.

Garrido Periñán, J. J. (2017). En busca del sí mismo perdido del Dasein: un diálogo entre Kafka y Heidegger en torno a la cuestión de la culpabilidad y la mismidad. Endoxa: Series Filosóficas 40, 159-182.

Garrido Periñán, J. J. (2018). Horizontes fenomenológicos de la espacialidad en Ser y Tiempo: la relevancia del ser-en como vía de acceso a la mismidad del Dasein. Eidos: Revista de Filosofía, 29, 150-174.

32 La bibliografía acerca de la Kehre es inmensa (Hermann, 1994: 65-84; Fräntzki, 1985; Rosales, 1984: 241-262 y Richardson, 1963: 212-262), pero hay una cierta unanimidad sobre su definición entre los investigadores más reputados. Estimo, grosso modo, que Kehre refleja el intento llevado a cabo, por parte de Heidegger, de pensar la relevancia fenomenológica del ser allende la analítica existencial, en su sustitución por una tarea "des-subjetivizadora", que entiende el ser como un fenómeno histórico-epocal, según el cual, el Dasein no es sujeto activo en el esclarecimiento del sentido del ser, sino, antes bien, pasivo, pues debe recoger lo que se da históricamente, el envío de su época [Epoche]. No es de extrañar, por tanto, que el lenguaje empleado por Heidegger, después de lo que hemos llamado Kehre, raye con el dictum poético: la tarea consistía en decir lo in-decible, aquello para lo que no estamos preparados históricamente: Hölderlin y los primeros griegos. 
Garrido Periñán, J. J. (2019a). La aportación no-apofántica de la disposicón afectiva y la mismidad del Dasein: análisis fenomenológico a partir del momento estrictural ser-en. Pensamiento: Revista de Investigación e Información Filosófica, 75, (en prensa).

Garrido Periñán, J. J. (2019b). Caminos y esbozos para una apertura fenomenológica del horizonte mismidad desde la constitución ontológica del mundo en Ser y Tiempo. Trans/form/açao: Revista de Filosofía, 42, (en prensa).

Heidegger, M. (1975). Der Grundprobleme der Phänomenologie. II Abteilung, Band 24. Frankfurt a. M.: Vittorio Klostermann.

Heidegger, M (1976a). Logik. Die Frage nach der Wabrheit. II. Abteilung, Band 21. Frankfurt a. M.: Vittorio Klostermann.

Heidegger, M. (1976b). Wegmarken. Gesamtausgabe, I. Abteilung, Band 9. Frankfurt a. M.: Vittorio Klostermann.

Heidegger, M. (1977). Phänomenologische Interpretation von Kants Kritik der reinen Vernunft, II. Abteilung, Band 25. Frankfurt a. M.: Vittorio Klostermann 1995.

Heidegger, M. (1983). Die Grundbefriffe der Metaphysik. Welt-Endlichkeit-Eisamkeit, II. Abteilung, Band 29/30. Frankfurt a. M.: Vittorio Klostermann.

Heidegger, M (1988a). Schelling: Vom Wesen der Menschlichen Freiheit, II Abteilung, Band 42. Frankfurt a. M.: Vittorio Klostermann.

Heidegger, M. (1988b). Ontologie (Hermeneutike der Factizität). II Abteilung, Band 63. Frankfurt a. M.: Vittorio Klostermann.

Heidegger, M. (1991). Kant und das Probleme der Metaphysik, I. Abteilung, Band 3. Frankfurt a. M.: Vittorio Klostermann.

Heidegger, M. (1992). Platon: Sophistes. II. Abteilung, Band 19. Frankfurt a. M.: Vittorio Klostermann.

Heidegger, M. (1995). Phänomenologische Interpretation von Kants Kritik der reinen Vernunft, II. Abteilung, Band 25. Frankfurt a. M.: Vittorio Klostermann.

Heidegger, M. (2002). Sein und Zeit. Tubingen: Max Niemeyer.

Heidegger, M. (2006). Sery Tiempo. (J. E. Rivera, Trad.). Madrid: Trotta.

Hermann, F-W. (1994). Wege ins Ereignis: zu Heideggers Beiträgen zur Philosophie. Frankfurt a. M.: Vittorio Klostermann.

Jáuregui, C. (2011). Subjetividad y Auto-conocimiento en la filosofía trascendental de I. Kant. Ágora: Papeles de Filosofía, 30(1), 31-47.

Kant, I. (1920). Logik. Ein Handbuch zu Vorlesungen. En B. Jäsche \& W. Kinkel (Eds.). Band 4 (pp. 1-150, 503-508). Leipzig: Felix Meiner.

Kant, I. (1993). Opus postumun. (E. Förster \& M. Rosen, Trads.). New York: Cambridge University Press.

Kant, I. (1998). Kritik der reinen Vernunft. Hamburg: Meiner Verlag.

Kant, I. (2001a). Kritik der Urteilkraft. Hamburg: Meiner Verlag.

Kant, I. (2001b). Prolegomena zu einer jeden künftigen Metaphysik, die als Wissenschaft wird auftreten können. Hamburg: Felix Meiner.

Kant, I. (2003). Kritik der praktischen Vernunft. Hamburg: Meiner Verlag.

Kant, I. (2005). Crítica de la razón pura. (P. Ribas, Trad.). Madrid: Taurus. 
Moya, E. (2004). Heidegger, un kantiano sedicente. Comentarios al Curso de Marburgo 1925-1926 sobre Kant. Daimon: Revista Internacional de Filosofía, 33 , 225-234.

Reis, R. (2018). Dos Reis (2018: 121-142). El concepto existencial de ciencia. En R. Rodríguez (ed.), Guia Comares de Heidegger (pp. 121-142). Granada: Editorial Comares.

Richardson, W.-J. (1963). Heidegger, Through Phenomenology to Thought. The Hague: Martinus Nijhoff.

Rodríguez, D. (2006). Imaginations transcedentales. De la percée phénoménologique à la revolution copernicienne. Alter: Revue de Phénoménologie, (14), 327-3522.

Rosales, A. (1984). Zum Problem der Kehre im Denken Heideggers. Zeitschrift für philosophische Forschung, 38, 241-262.

Torretti, R. (2005). Manuel Kant: Estudio sobre los fundamentos de la filosofía crítica. Santiago: Ediciones Universidad Diego Portales.

Vigo, A. (2010). Libertad como causa. Heidegger, Kant y el problema metafísico de la libertad. Anuario Filosófico, 43(1), 61-181.

Vigo, A. (2017). Contingencia y finalidad. Kant y la perspectiva reflexiva sobre la naturaleza. Open Insight, 8(13), 123-159.

Zuckert, R. (2007). Projection and Purposiveness. Heidegger's Kant and the Temporalization of Judgment. En S. Crowell \& S. J. Malpas (eds.), Trascendental Heidegger (pp. 215-231). Stanford/California: Standford University Press.

Sumario: Introducción; 1. Sensibilidad y afección: primera forma de conocimiento; 2. Temporalidad: auto-afección del sí-mismo y el carácter configurador de la imaginación; 3. La aparición del sí-mismo/mismidad: resignificador de la temporalidad; Conclusiones; Referencias. 